\title{
FORMAÇÃO CONTINUADA: O QUE PENSAM OS PROFESSORES DA ESCOLA PÚBLICA EM ITUIUTABA?
}

\author{
Monalisa Lopes dos Santos Coelho. Universidade Federal de Uberlândia/Faculdade de \\ Ciências Integradas do Pontal - monalisainss@ gmail.com
}

\begin{abstract}
RESUMO: Este texto é o resultado de um estudo acerca da formação continuada de professores numa escola pública e estadual e teve como objetivo compreender como se configura esta formação na escola Y, em Ituiutaba, Minas Gerais. Enquanto alunas do curso de pedagogia da UFU, inseridas no Pibid, que atuam nesta escola, nos interessamos em conhecer o que pensam os professores da educação básica. Assim, indagamos como se configura a formação continuada dos professores da referida escola; quais cursos eles fazem; em quais instituições de ensino eles fazem a formação; qual o tempo de duração destes cursos; se o governo federal, estadual, e municipal oferecem este tipo de formação; e se existem fatores que motivam esta formação, para favorecer a conciliação desta com as atividades docentes nos anos iniciais do Ensino Fundamental. Pautamo-nos nos posicionamentos de Ferreira (2006), Freitas (2007) e Dias (2012), e a partir desse referencial teórico utilizamos o método da entrevista como nosso principal instrumento metodológico de pesquisa na referida escola. Nos resultados, verificamos que de fato estes professores realizam formação continuada. Entretanto, detectamos desafios e obstáculos para que estes se vejam totalmente motivados e interessados em continuar em formação, diante do como esta formação tem acontecido no município.
\end{abstract}

Palavras-chave: Formação Continuada de Professores. Escola Pública. Educação Básica.

\begin{abstract}
This text is the result of a study about the teacher's continuous formation in a public school and aimed to understand how this formation in Y school, in Ituiutaba, Minas Gerais is. As students of the UFU pedagogy course, inserted in the Pibid, who work in this school, we are interested in knowing what teachers of basic education think. Thus, we inquire how the teacher's continuous formation of that school is configured; What courses they do; In which educational institutions they do the training; how long these courses last; if the federal, state, and municipal governments offer this type of training; and if there are factors that motivate this formation, to favor the conciliation of this with the teaching activities in the initial years of Elementary School. We take the positions of Ferreira (2006), Freitas (2007) and Dias (2012), and from this theoretical reference we use the interview method as our main research methodological instrument in the mentioned school. In the results, we verified that in fact these teachers carry out continuous training. However, we detected challenges and obstacles so that they are totally motivated and interested in continuing in formation, in view of how this formation has happened in the municipality.
\end{abstract}


Keywords: Continuing Teacher Education. Public school. Basic education.

\section{INTRODUÇÃO}

Nos dias atuais, a temática da formação de professores tem sido um assunto recorrente nos debates e pesquisas dos intelectuais brasileiros. Este tema é tanto atual quanto antigo, e há uma grande produção acadêmica sobre o assunto em questão. Com base em alguns autores, tentou-se realizar uma retrospectiva dessa formação bem, como de sua implementação.

No Brasil, de acordo com Freitas (2002; 2007), a configuração da formação de professores respondeu ao modelo de expansão do Ensino Superior realizado na década de 1990, no âmbito das reformas do Estado, que esteve subordinado às recomendações dos organismos internacionais. A formação inicial foi caracterizada pela criação dos Institutos Superiores de Educação e pela diversificação e flexibilização da oferta dos cursos: normais superiores, pedagogia, licenciaturas, cursos especiais e cursos a distância, para poder atender a crescente demanda pela formação superior.

A formação que se segue à inicial é a continuada, caracterizada por qualquer tipo de atividade que auxilie no desenvolvimento profissional, realizada após a graduação ou após o ingresso na carreira docente. Outro autor que defende a importância dessa formação e que explica como ela deve acontecer é Ferreira (2006):

\footnotetext{
Nesta perspectiva, a Formação Continuada deve ser realizada através de momentos diários de estudo, reflexão, planejamento e avaliação, de modo a assegurar esse processo. Portanto, não faz sentido os educadores pensarem que, ao concluírem a graduação, ou seja, sua formação inicial, não precisam mais se dedicar aos estudos para atuar na profissão docente. (FERREIRA, 2006, p.20):
}

Desta maneira, de acordo com Freitas (2007), para implementar a formação continuada, os Cursos de EAD (Educação a Distância) foram amplamente adotados entre os anos de 1997 a 2006, para preparar os professores pelo País. Entretanto, mesmo que estes cursos tenham atendido as necessidades de formação dos professores na área de informática, eles não responderam às necessidades reais dos educadores: as competências para atuar como educadores nas escolas. Bem como afirma Freitas (2007, p. 1209):

Este modelo, desenvolvido à distância através de mídias interativas e novas tecnologias da informação e comunicação, se organiza em projetos de cursos que partem do trabalho dos professores, exclusivamente em sua dimensão prática, reduzindo as possibilidades da mediação pedagógica necessária no processo de ensino, e não se sustenta quando confrontado com as condições de produção da vida 
material e da organização da escola e da educação, que demandam outras habilidades, capacidades e competências de seus educadores.

Sendo assim, conforme explicita Freitas (2007), as ações do MEC nos anos 2000 passaram a ser orientadas na direção da continuação de programas de caráter continuado e compensatório, destinados à formação de professores leigos, na modalidade de EAD, para que estes cursos pudessem auxiliar os professores que estão em exercício nos sistemas de ensino e também aqueles já formados inicialmente e em exercício.

Segundo Dias (2012), as diretrizes do Plano Nacional da Educação (PNE) (2001) anunciam que a formação continuada dos profissionais da educação pública deveria ser garantida pelas secretarias estaduais e municipais de Educação, incluindo a coordenação, o financiamento e a manutenção dos programas como ação permanente, em parcerias com universidades e instituições de ensino superior.

Diante do exposto, mesmo reconhecendo como deve ser tal formação, observamos, sob a perspectiva de Dias (2012), a existência de um problema nacional na maneira como a formação continuada tem se dado em nosso país. Esta autora discorre que nas políticas públicas, para oferecer a formação continuada de professores, foi constatado que em todos os estados brasileiros e na maioria das cidades metropolitanas essas atividades foram desenvolvidas pelos próprios profissionais das secretarias de Educação ou por consultorias contratadas. Além disso, a autora aponta duas evidências:

(1) essas formações tornaram-se compensatórias, para suprir a precariedade da formação inicial; perdendo, assim, o propósito da "formação continuada" que é o aprimoramento do profissional nos avanços, renovações e inovações da sua área; e (2) a expansão de cursos de extensão, graduação e pós-graduação, sob o rótulo "formação continuada" foi tão grande que o acompanhamento e a avaliação de todos eles tornaram-se inviável para o governo, o que pode colocar em dúvida a validade, a eficácia e a qualidade de dessas formações (DIAS, 2012, p.17).

Assim sendo, e diante dessa breve retrospectiva histórica brasileira, neste artigo, faremos uma análise de como se configura a formação continuada dos professores da escola $\mathrm{Y}$, apresentando as dificuldades presentes e o que pensam estes docentes ao realizar os cursos de qualificação.

A escola pesquisada é foco da atuação do Programa Institucional de Bolsas de Iniciação à Docência (Pibid), do Curso de Pedagogia da Universidade Federal de Uberlândia (UFU), da Faculdade de Ciências Integradas do Pontal (Facip) e, enquanto programa inicial de formação de professores, possibilita a inserção do licenciando na escola. Neste sentido, buscamos identificar como se dá esta formação continuada dos professores, sob a perspectiva 
inicial das alunas "pibidianas" que entrevistaram boa parte destes professores, e estão experienciando momentos de vivência no referido espaço escolar.

\section{OBJETIVOS}

O objetivo principal deste estudo é compreender como se configura a formação continuada dos professores da Escola Y, em Ituiutaba, Minas Gerais. Os objetivos específicos são: indagar os motivos que levam estes professores a realizá-la, como eles fazem, quais cursos eles fazem; quais são as instituições de ensino nas quais eles fazem; qual o tempo de duração destes cursos; se os governos federal, estadual, e municipal oferecem este tipo de formação; e também verificar a existência de fatores motivantes ou não para estes docentes se interessarem em fazer ou continuar fazendo esta formação, tendo em vista que precisam conciliar a mesma com a sua jornada de trabalho nos anos iniciais do Ensino Fundamental.

\section{METODOLOGIA}

Realizamos uma pesquisa bibliográfica sobre a formação continuada de professores, e, em campo, entrevistamos treze professores da instituição para investigar em qual curso superior se deu a formação inicial e se estavam se qualificando profissionalmente em formação continuada nos últimos cinco anos. Após cinco meses, aplicou-se um questionário, com o mesmo grupo de professores, apenas para a obtenção de dados mais específicos, como o nome dos cursos de formação continuada realizados, quando, onde, como, e a carga horária de duração dos mesmos, sendo que o método da entrevista foi o mais relevante nesta pesquisa.

\section{RESULTADOS E DISCUSSÃO}

Nas entrevistas realizadas pelas alunas do Pibid Alfabetização I e II na escola Y, com as treze professoras do $1^{\circ}$ ao $5^{\circ}$ ano, constatamos que a formação inicial das professoras entrevistadas se deu no curso de Pedagogia. Nos últimos cinco anos, elas fizeram de 1 a 12 cursos de formação continuada, e apenas uma afirmou não ter feito nenhum curso neste período. A seguir, falaremos dos cursos presenciais e após falaremos dos cursos de Educação a Distância.

Ao indagar sobre esta formação na rede estadual, todas as professoras afirmaram que existe uma política de formação continuada por parte do estado de Minas Gerais e que ele 
oferece condições para que ela ocorra. Nove professoras fizeram apenas o curso Pacto Nacional de Alfabetização na Idade Certa, e sete de todas as entrevistadas mencionaram que fizeram este e outros cursos além desse. Quatro outras que não fizeram o Pacto, disseram ter feito outros cursos nos últimos cinco anos que antecedem a pesquisa.

Deste modo, buscamos entender o que é o Pacto, feito pelas nove entrevistadas. Segundo o site do Ministério da Educação e Cultura (MEC), o Pacto Nacional pela Alfabetização na Idade Certa é curso presencial de dois anos para os professores alfabetizadores dos anos iniciais do Ensino Fundamental. Ele é um compromisso formal assumido pelo governo federal, para assegurar que todas as crianças estejam alfabetizadas até os oito anos de idade, ao final do $3^{\circ}$ ano do Ensino Fundamental, e é ministrado em Instituições de Ensino Superior (IES), ou em algum espaço oferecido pela prefeitura do município. Ele dispõe de uma carga horária de 120 horas por ano, baseado no Programa PróLetramento (BRASIL, 2014).

O Pró-Letramento é um programa de formação continuada de professores, para a melhoria da qualidade de aprendizagem da leitura/escrita e de Matemática. Duas das treze professoras entrevistadas afirmaram ter feito o Pró-Letramento de Língua Portuguesa e de Matemática. Este curso é realizado pelo MEC, em parceria com universidades que integram a Rede Nacional de Formação Continuada, podendo participar todos os professores que estão em exercício, nas séries iniciais do Ensino Fundamental das escolas públicas (BRASIL, 2014).

Sobre como tem acontecido o Pacto na escola Y, três entrevistadas que realizaram o curso afirmaram que em 2013 aconteceu o Pacto de Língua Portuguesa, e em 2014 ocorreu o de Pacto de Matemática. A seguir, a professora, que denominamos de P17, comenta como foi sua experiência, ao aprender a trabalhar de forma mais lúdica com seus alunos:

\footnotetext{
O ano passado fizemos o da Língua Portuguesa, esse ano o de Matemática, nessa questão da gente estar trabalhando com jogos lúdicos pra melhorar o raciocínio lógico, melhorar o aprendizado das crianças, pois, a matemática é muito difícil, porque ela se torna um pouco abstrata para as crianças e aí, ah... A proposta é isso, trabalhamos de maneira mais lúdica na sala de aula. (P17)
}

Continuando a falar sobre o Pacto, quatro entrevistadas comentaram acerca da carga horária do curso e como ele é oferecido, porém, é preciso acrescentar que, de acordo com três destas quatro professoras, o estado de Minas Gerais, oferece condições viabilizando um recurso financeiro mensal de $\mathrm{R} \$ 200,00$ (duzentos reais) para incentivar a permanência neste curso, bem como afirma uma das professoras a seguir: 
Participo do Pacto [...] são 10 sábados [...], é das 8:00hs ao meio dia e das 13:00hs as 17:00hs são dez módulos de 8 horas, [...] o Pacto é um que todos os professores de $1^{\circ}, 2^{\circ}$ e $3^{\circ}$ ano são estimulados a fazerem, [...] é um curso maravilhoso nos auxilia muito [...] mas para alguns ele dá uma bolsa de 200 reais, mas para outros não, que eu saiba não [...] (P13).

Ainda analisando as falas destas professoras, percebemos que em contrapartida às vantagens oferecidas pelo governo para maior participação docente no Pacto, existem também três fatores desmotivantes, que são: i) os professores precisam aguardar ser chamados para fazer o curso, e esta bolsa mensal não é concedida a todos, pois há o critério da não participação em outros cursos quando se aceita participar deste; ii) este curso só é oferecido em turno extra, aos sábados, e assim ele se torna muito exaustivo para ser conciliado com as rotinas docentes semanais; iii) o Pacto é oferecido somente para os professores do $1^{\circ}$ ao $3^{\circ}$ ano, e os professores capacitados para trabalharem com turmas destes anos, ao assumirem turmas de $4^{\circ}$ e $5^{\circ}$ anos, não aproveitam genuinamente os conhecimentos apreendidos no curso, nem os utilizam de forma prática em sala de aula, além de terem que buscar outros conhecimentos para dar aula nessas novas turmas. Deste modo, destacamos o que os professores pensam acerca das vantagens e desvantagens que este curso tem oferecido.

Terminada a análise do Pacto, mas ainda falando dos cursos presenciais, na escola Y, duas professoras realizaram os seguintes cursos oferecidos pelo Centro Municipal de Assistência Pedagógica e Aperfeiçoamento Permanente de Professores (Cemap), com duração de 40 a 80 horas: Inclusão; Brincar Lúdico no Fundamental 1; Musicalização; Dificuldades de Aprendizagem; A Arte como Ferramenta de Ensinar. De acordo com o site da Prefeitura Municipal de Ituiutaba, o Cemap tem o objetivo de investir na atualização de conhecimentos e capacitação constante dos profissionais da área da Educação de Ituiutaba. Em parceria com a Prefeitura Municipal, ele acontece na Secretaria Municipal de Educação, Esporte e Lazer (ITIUTABA, 2014). Assim, percebemos que existem cursos desta natureza disponíveis gratuitamente no município.

A partir de agora, falaremos dos cursos na modalidade de educação a Distância $(\mathrm{EaD})$. De todas as entrevistadas, apenas uma professora afirmou ter participado de uma Pósgraduação em Educação Especial com 300 horas, oferecida gratuitamente no site do Magistra. De acordo com informações oficiais deste portal de acesso, o Magistra é a Escola de Formação e Desenvolvimento Profissional de Educadores de Minas Gerais, com o objetivo de promover a formação e a capacitação de educadores, de gestores e demais profissionais da Secretaria Estadual de Educação (SEE), nas diversas áreas do conhecimento e em gestão 
pública e pedagógica. Além disso, esta é denominada como a escola da escola, e é uma das maiores do Brasil (MINAS GERAIS, 2014).

Ainda nas entrevistas realizadas, foi observado que duas outras professoras participaram de outros cursos $(\mathrm{EaD})$ em parceria com a Universidade Aberta Integrada de Minas Gerais (Uaitec). O primeiro é oferecido pelo Serviço Nacional de Aprendizagem Comercial (Senac), e o segundo é oferecido pelo Instituto Federal do Triângulo Mineiro (IFTM), bem como afirma a primeira professora: “[...] eu já fiz um de cuidador infantil, é do Senac em parceria com a Uaitec [...] para trabalhar em creche" (P1), e a segunda professora:

[...] participo de um curso [...] oferecido pelo IFTM [...] que chama Multi Meios Didáticos, ele vai auxiliar o professor a utilizar os Multi meios que hoje estão na moda, [...] auxiliando muito no desenvolvimento dos alunos, é tanto o matemático, como nas outras áreas (P12).

Sobre esta oferta de cursos, segundo Dias (2012), o governo criou ao longo da última década o Sistema Universidade Aberta do Brasil (UAB), em parceria com a Secretaria de Educação a Distância do MEC, que tem como objetivo prioritário promover a formação inicial e continuada de professores que atuam na educação básica, e ainda dos dirigentes, gestores e trabalhadores da educação básica, utilizando metodologias de educação a distância.

De 2007 a julho de 2009, foram instalados 557 polos de apoio presencial por todo o Brasil, e um desses polos criados foi a Uaitec, na cidade de Ituiutaba. Diante disto, podemos perceber que há um empenho governamental quanto à oferta de cursos na modalidade (EaD) para docentes em todo o País, e que isto se deu também nesta cidade.

Além dessas entrevistadas mencionadas até o momento, outra professora mencionou que apesar de ter realizado somente o curso do Pacto, ela tem ciência da existência de outros dois cursos disponibilizados gratuitamente pela Superintendência Regional de Ensino (SER), oferecidos pelo governo estadual, que são: o curso de informática do Sistema Operacional Linux, e o curso de Linguagem Brasileira de Sinais (Libras), e também fala a respeito dos desafios que existem para a realização destes cursos, como afirma a seguir:

[...] a Superintendência oferece, mas você tem que fazer a inscrição, ele é extra turno [...] Porque a escola não trabalha com Windows, ela trabalha com o [...] Linux, então ela oferece para você aprender, e ir lá trabalhar, [...] uma vez por ano ou duas, [...] oferece cursos, para quem se interessa na escola participar. [...] o Curso de Libras é oferecido, mas também é pra quem se interessa [...] a condição é o extra turno, se você tem como ir. Às vezes você quer fazer, mas não tem como ir, porque às vezes é ministrado à noite, e você estuda à noite [...] (P3). 
Diante desta fala, podemos perceber que o governo de Minas Gerais também oferece cursos de formação continuada em parceria com a SRE. Todavia, foi percebido que seria fundamental que o governo analisasse as dificuldades que são impostas aos professores, como a falta de transporte, a oferta do curso em turno extra de trabalho, e a falta de tempo, o que acaba desmotivando os professores, e impedindo que essa formação ocorra. Ou seja, há a existência dos cursos, mas ainda faltam ações para resolver as dificuldades dos professores, para que compareçam as formações.

Sendo assim, enquanto discentes participantes do Pibid, subprojeto Pedagogia na escola Y, nas análises feitas com as treze professoras da escola, verificamos que acontecem ações dos governos federal, estadual e municipal, e que a maioria dos professores faz formação continuada, pois o governo tem se proposto a manter as instituições de ensino que disponibilizam estes cursos, aqui já elencadas.

Entretanto, identificamos também a existência de desafios e obstáculos que dificultam o acesso e a permanência destes docentes nestes cursos de formação continuada, tornando-se fatores desmotivantes, como já fora pontuado até aqui, no caso do Pacto e no caso dos cursos disponíveis na SRE, oferecidos no município. Contudo, um dos fatores principais, e talvez o mais influenciador, seja a falta de tempo dos docentes para procurar tais cursos, pois, bem como afirma a professora P13: “[...] têm vários outros cursos, só não fazem por causa do tempo [...]". Assim, elencamos o fator da falta de tempo como o fator de influência maior, pois a maioria dos cursos tem que ser realizada em turno extra, ou seja, além da jornada de trabalho docente já desempenhada.

\section{CONSIDERAÇÕES FINAIS}

A temática aqui discutida não se esgota nesta pesquisa, porque carece de discussões que ampliem e desenvolvam novas estratégias, para maior adesão dos educadores em exercício na realização de novos cursos de maneira satisfatória. Diante deste estudo, entendemos que a maioria dos professores desta escola está, em princípio, preocupada com a melhoria da sua prática pedagógica, para atualizar seus conhecimentos e desenvolver novas de estratégias de ensino, aliando-se aos recursos e novas tecnologias disponíveis hoje para estarem à altura das exigências de ensino propostas para a educação.

Concluímos que estes professores deixam de continuar em formação por causa de todos os fatores desmotivantes até aqui explanados. Mas, além desses, inferimos que existe outro fator desmotivante que os impedem de continuarem a estudar. Embora não tenham sido 
identificadas nas falas dos entrevistados, levantamos a hipótese de que os professores também deixam de realizar novos cursos devido à desvalorização do professor nas carreiras docentes estaduais, pois só há progressão de salário com a pós-graduação de 360 horas. Supomos que devido à maioria dos cursos aqui mencionados apresentar uma carga horária inferior a 200 horas e não trazer progressão salarial, não aumentando a remuneração docente, estes professores desanimam em continuar a estudar, por causa desta realidade dada no âmbito de ensino estadual. 


\section{REFERÊNCIAS BIBLIOGRÁFICAS}

BRASIL, 2014. Formação continuada do Pacto Nacional pela Alfabetização na Idade Certa. Disponível em: <http://pacto.mec.gov.br/component/content/article/26-eixos-deatuacao/54-formacao>. Acesso em 20 de fev. de 2015.

BRASIL, 2013. Pacto Nacional pela Alfabetização na Idade Certa. Disponível em: <http://pacto.mec.gov.br/o-pacto>. Acesso em 19 de fev. de 2015.

BRASIL, 2013. Pró-Letramento. Disponível em: $<$ http://mecsrv125.mec.gov.br/index.php?option=com_content\&view=article\&id=12346\&Ite mid=700>. Acesso em 19 de fev. de 2015.

DIAS, Simome Chaves. Políticas públicas de formação continuada de professores: a experiência no município de Itajaí. Rio de Janeiro: UNESA, 2012. 107 p. Dissertação (Mestrado em Educação) - Programa de Pós-graduação em educação, Universidade Estácio de Sá, Rio de Janeiro, 2012.

FERREIRA, Naura Syria Carrapeto. Formação continuada e gestão da educação no contexto da "cultura globalizada". In: FERREIRA, Naura Syria Carrapeto (org.). Formação continuada e gestão da educação. - 2a Ed. São Paulo: Cortez, 2006.

FREITAS, Helena Costa Lopes de. Formação de Professores no Brasil: 10 anos de embate entre projetos de formação. Educ. Soc., Campinas, vol. 23, n. 80, setembro/2002, p. 136-167.

FREITAS, Helena Costa Lopes de. A (nova) política de formação de professores: a prioridade postergada. Educ. Soc., Campinas, vol. 28, n. 100 - Especial, p. 1203-1230, out. 2007.

ITUIUTABA, 2014. Prefeitura de Ituiutaba: CEMAP - Centro Municipal de Assistência Pedagógica e Aperfeiçoamento Permanente de Professores. Disponível em: $<$ http://www.ituiutaba.mg.gov.br/antigo/? $\mathrm{id}=2136 \& \mathrm{i}=62 \& \mathrm{t}=$ Not\%C3\%ADcias\&act $=\mathrm{ler} \& \mathrm{c}=\mathrm{n}$ oticias\&ca=3>. Acesso em 09 de jun. de 2015.

MINAS GERAIS, 2014. Magistra. Disponível em: <http://magistra.educacao.mg.gov.br/index.php/institucional/o-que-e-a-magistra>. Acesso em 20 de fev. de 2015. 